\title{
Adoption of recommended dairy farming practices by farmers in Maharashtra under Kamdhenu Dattak Gram Yojana
}

\author{
Sanjay Vasant Kad ${ }^{1}, K_{S}$ Kadian $^{2}$, Raju R${ }^{3}$ and Suresh Kad ${ }^{4}$
}

Received: 03 August 2020 / Accepted: 13 August 2020 / Published online: 27 October 2020

(C) Indian Dairy Association (India) 2020

\begin{abstract}
The present study aimed to measure the extent of adoption of recommended dairy farming practices by farmers of Pune and Nashik divisions of Maharashtra which were selected based on livestock population and milk production in the year 2018-19. From each division two districts were selected randomly and from each district two blocks were selected randomly. From each block one adopted and one non-adopted village under the Kamdhenu Dattak Gram Yojana scheme were selected from each village 15 dairy farmers were selected on random basis. Overall, 240 dairy farmers were selected, as the respondents for this study constituting 120 beneficiarie farmers and 120 non-beneficiaries of the Kamdhenu Dattak Gram Yojana. The quantitative and qualitative data were collected through interview schedule, discussion, observation and available secondary sources. Findings indicated that the most of beneficiaries $(43.33 \%)$ were in medium level overall adoption and majority of non-beneficiaries $(62.50 \%)$ had fallen in low level of overall adoption category on recommended dairy farming practices covering breeding, feeding, health, general management and waste management practices. The overall adoption index of recommended dairy farming practices of beneficiaries (75.31) was found to be more compared to non-beneficiaries (66.75) of the scheme and found highly
\end{abstract}

${ }^{1}$ ICAR-Central Soil Salinity Research Institute, Regional Research Station, Bharuch-392012

${ }^{2}$ Dairy Extension division, ICAR-National Dairy Research Institute, Karnal-132001

${ }^{3}$ Division of Social Science Research, ICAR-Central Soil Salinity Research Institute, Karnal-132001

${ }^{4}$ Department of Animal Husbandry, Government of Maharashtra, Pune 410501

Sanjay Vasant $\operatorname{Kad}(\square)$

ICAR-Central Soil Salinity Research Institute,

Regional Research Station, Bharuch-392012, Gujarat.

Email: sanjayndri@gmail.com, kad.sanjay@icar.gov.in; Phone: 7988153714 significant at 5 per cent level of probability using ' $Z$ ' test. Based on adoption index, maximum adoption of dairy farming practices was found in case of Breeding practices, whereas minimum adoption was found in case of Waste management practices in both beneficiaries and non-beneficiaries of the scheme. The results clearly indicated that the Kamdhenu Dattak Gram Yojana had created positive impact on the adoption level of the beneficiaries of scheme by adopting higher recommended dairy farming practices compared to the non-beneficiaries of the scheme.

Keywords: Adoption index, adoption, dairy farming practices, Kamdhenu Dattak Gram Yojana

\section{Introduction}

Dairy is having potential to improve the economic condition of the rural poor to fulfill the national commitment. This vast potential of dairy farming can be harness by efficient management of livestock production which, in turn, needs updated or latest scientific, economic and technical information to the farmers. Adoption and diffusion of dairy innovations is very essential to enhance the productivity of livestock and in turn income to dairy farmers' upto desired extent (Parihar et al. 2019). The slow pace of adoption of improved dairy farming practices is attributed to various factors. A firsthand knowledge of these factors to the extension personnel would create the speedy adoption of dairy innovations in the villages.

Therefore, a study entitled "Impact of Kamdhenu Dattak Gram Yojana on Dairy Farmers in Maharashtra: An Appraisal from Farmers Perspective" was conducted with specific objective to measure the adoption of the recommended dairy farming practices by the respondents in Maharashtra. The Kamdhenu Dattak Gram Yojana was launched by the Maharashtra government in October, 2010. The aim of the scheme was implementation of various essential activities of animal husbandry relevant to the breeding of animals, health care and disease control, general management and feed-fodder production in the selected village/cluster of villages in all the districts with a focused approach and mission mode basis. Under this programme, each Animal Health Centre of State Animal Husbandry Department has to adopt one village 
which is having 300 or above breedable cattle and buffalo population. Based on which a large number of technologies suitable for farming situations have been implemented in adopted villages for the overall development of dairy farmers by increasing the income from dairying.

\section{Materials and Methods}

\section{Study area}

The present study was conducted in the Pune and Nashik divisions of the state which constitute more than $2 / 3^{\text {rd }}$ bovine population of the state comprising mainly crossbred's cows and buffaloes which contribute 68.69 per cent of total milk production of state. The milk production of Pune and Nashik division are 41.80 percent and 26.88 percent, respectively of the total milk production of state in 2017-18 (GOM, 2019). The Kamdhenu Dattak Gram Yojana was launched initially on pilot basis in these divisions of Maharashtra since 2011-12. The state government has set target for implementation of this scheme through animal husbandry and dairy development department of state.

\section{Study approach and sampling methods}

A triangulation approach using both qualitative and quantitative methods were used in the study. A multistage sampling procedure was followed. Pune and Kolhapur districts from Pune division and Nashik and Ahmednagar districts from Nashik division were selected randomly. From each district two blocks were selected randomly. From each block one Kamdhenu Dattak Gram Yojana adopted village and one non-adopted village were selected randomly. From each village 15 dairy farmers were selected randomly. Thus, in total, 120 dairy farmers from adopted villages under Kamdhenu Dattak Gram Yojana and 120 dairy farmers from non-adopted villages were selected using Random Sample Technique for this study.

\section{Method of data collection}

Data were collected using a well-structured interview schedule during October, 2018 to March, 2019 period. In the present study, adoption was measured by collecting all the relevant items related to recommend dairy farming practices with consultation veterinarians and SAUs in the study area, and also concerned literature and previous research studies. The selected items were divided in following heads: feeding, breeding, health care, general management and waste management practices. The response of the respondents were taken against each of the practice on a three point continuum representing 'Adopted' $(A)$, 'Partially adopted' (PA), and 'Not adopted' (NA) adopted with scores of 2,1 and 0 , respectively.

\section{Data analysis}

The respondents were categorized into low, medium and high categories of adoption on the basis of Cumulative square root frequency method in different aspects of adoption as well as overall adoption of improved dairy farming practices. An adoption index was calculated for comparison of adoption of different recommended dairy farming practices among beneficiaries and non-beneficiaries of the scheme. The following formula was used to measure the adoption index of different aspects of improved dairy farming practices.

$$
\text { Adoption Index }=\frac{\text { Score obtained by an individual }}{\text { Maximum obtainable score }} \times 100
$$

\section{Results and Discussion}

The level of adoption of recommended dairy farming practices by beneficiaries would give an indication about how much impact taken place due to implementation of Kamdhenu Dattak Gram Yojana.

\section{Adoption level of breeding practices}

The results in the Table 1 revealed that half of beneficiaries $(50.00 \%)$ were found under medium level of adoption. Whereas, 25.00 percent beneficiaries were found in equally both high and low level of adoption categories. On the other hand, in case of non-beneficiaries, the majority $(60.00 \%)$ of respondents had low level of adoption of breeding practices followed by 24.17 and 15.83 per cent non-beneficiaries were found in medium and high level of adoption of breeding practice. This improvement among the beneficiaries might be due to motivation and technical help by the animal husbandry department officials to more adoption of breeding practices under Kamdhenu Dattak Gram Yojana. The overall adoption index of beneficiaries (81.83) is found higher compared to non-beneficiaries (73.08) of scheme. Similarly, Divekar et al. (2016) also observed parallel adoption index (81.40) to that of beneficiaries of present study in breeding management practices.

\section{Adoption level of feeding practices}

In the feeding practices, Table 1 revealed that most of the beneficiaries $(47.50 \%)$ were found in medium level of adoption and 41.67 per cent of non-beneficiaries had low level of adoption of feeding practices. Whereas, about 28.33 and 24.17 per cent of beneficiaries were found in low and high level of adoption of the breeding practices, respectively. In case of non-beneficiaries, 39.17 per cent of respondents were found in medium level of adoption. Only 19.17 per cent of non-beneficiaries had high level of adoption of breeding practices. Milk production mainly depends upon feeding of concentrate mixture, getting knowledge of preparation of balance feed and silage making through demonstration by veterinary officials and sufficient mineral mixture feeding to animals. 


\section{Adoption level of health practices}

Adoption of better healthcare practices is keeping animals from diseases free, consistent in milk production and good energy level of animal. It could be noted from Table 4.6 that the most of the beneficiaries (39.17\%) had medium level of adoption of health practice followed by 37.50 per cent of the beneficiaries were found in low level of adoption. In case of non-beneficiaries, the majority $(60.00 \%)$ of the non-beneficiaries had low level of adoption. This is mainly due to the veterinary officials of state government in beneficiary villages strictly following yearly schedule of vaccination, deworming by organizing camps at same time in village to contained disease infection spread to other animals. The overall adoption index of beneficiaries was found (78.96), which agreement with result reported by Divekar et al. (2016) in adoption index of different health practices by farmers was found 81.33 in Gujarat.

\section{Adoption level of general management practices}

The data presented in Table 1 inferred that in case of beneficiaries, the most of the beneficiaries (40.83\%) had medium level of adoption followed by 35.00 and 24.17 per cent were found in to low and high level of adoption of management practices, respectively. On the other hand, the majority of the nonbeneficiaries $(57.50 \%)$ were having low level of adoption of management practices. The high adoption of management practices by beneficiaries might be timely information of practices provided under the scheme. Maintaining daily account keeping and milk production records by dairy farmers might help to monitor loss and profit in dairy farming and milk yield of animal. Whereas, non-beneficiaries of scheme were less aware of these management practices and ignorance of record keeping and milk yield monitoring of animals.

\section{Adoption level of waste management practices}

The results presented in Table 1 revealed that 37.50 and 30.83 percent of the beneficiaries were found under medium and high level of adoption of waste management practices, respectively. About 31.67 per cent of the beneficiaries had low level of adoption of waste management practices. In case of non-beneficiaries, most of them (45.00\%) were found in medium level of adoption followed by 36.67 per cent had low level of adoption of waste management practices. Whereas, only 18.33 per cent of the nonbeneficiaries were found under high level of adoption of waste management practices. Beneficiaries had more adoption of dung pit availability for FYM making, biogas production and vermincompost making compared to non-beneficiaries. The reasons expressed by beneficiaries of scheme of adopted villages regarding more adoption due to more awareness through demonstration on waste management practices such as dung pit making which, vermi-compost making and biogas production and its importance (Ponnusamy and Devi, 2017). Another reason for more adoption FYM and vermi-compost, it used in their own field and also get additional income by selling remaining FYM and vermi- compost in market. The reasons cited for more adoption of Biogas in adopted villages by farmers were the biogas was required only installation cost and saved other cooking gas cost and also gives clean energy to them. The veterinary officials

Table 1 Distribution of respondents on the basis of adoption of recommended dairy farming practices

\begin{tabular}{llllc}
\hline Sl. No. & Particulars & Category & Beneficiaries & Non-beneficiaries \\
\hline 1 & Breeding practices & Low & $30(25.00)$ & $72(60.00)$ \\
& & Medium & $60(50.00)$ & $29(24.17)$ \\
& & High & $30(25.00)$ & $19(15.83)$ \\
2 & Feeding practices & Low & $34(28.33)$ & $50(41.67)$ \\
& & Medium & $57(47.50)$ & $47(39.17)$ \\
& & High & $29(24.17)$ & $23(19.17)$ \\
3 & Health practices & Low & $45(37.50)$ & $72(60.00)$ \\
& & Medium & $47(39.17)$ & $25(20.83)$ \\
& & High & $28(23.33)$ & $23(19.17)$ \\
4 & General management & Low & $42(35.00)$ & $69(57.50)$ \\
& practices & Medium & $49(40.83)$ & $26(21.67)$ \\
& & High & $29(24.17)$ & $25(20.83)$ \\
5 & Waste management & Low & $38(31.67)$ & $44(36.67)$ \\
& practices & Medium & $45(37.50)$ & $54(45.00)$ \\
& & High & $37(30.83)$ & $22(18.33)$ \\
6 & Overall practices & Low & $42(35.00)$ & $75(62.50)$ \\
& & Medium & $52(43.33)$ & $23(19.17)$ \\
& & High & $26(21.67)$ & $22(18.33)$ \\
\hline
\end{tabular}

Figures in parenthesis indicate percentage of the respondents 
Table 2 Extent of adoption of recommended dairy farming practices based on Adoption Index (AI) among beneficiaries and nonbeneficiaries

\begin{tabular}{|c|c|c|c|c|c|c|c|c|}
\hline \multirow[t]{2}{*}{ S. No } & \multirow[t]{2}{*}{ Particulars } & \multicolumn{2}{|c|}{$\mathrm{B}(\mathrm{n}=120)$} & $\mathrm{NB}(\mathrm{n}=120)$ & \multicolumn{3}{|c|}{ MeanDifference Percentdifference } & \multirow[t]{2}{*}{ 'Z' value } \\
\hline & & $\overline{\mathrm{AI}}$ & Rank & $\mathrm{AI}$ & \multicolumn{3}{|c|}{ Rank } & \\
\hline$\overline{1}$ & Breeding & 81.83 & $\mathrm{I}$ & 73.08 & $\mathrm{I}$ & 8.75 & 11.97 & $4.66^{*}$ \\
\hline 2 & Feeding & 76.98 & III & 70.83 & II & 6.15 & 8.68 & $2.15^{*}$ \\
\hline 3 & Health & 78.96 & II & 67.19 & III & 11.77 & 17.52 & $3.52 *$ \\
\hline 4 & General Management & 73.70 & IV & 65.99 & IV & 7.71 & 11.68 & $2.04 *$ \\
\hline 5 & Waste management & 56.94 & $\mathrm{~V}$ & 48.89 & $\mathrm{~V}$ & 8.06 & 16.48 & $1.86^{* *}$ \\
\hline \multicolumn{2}{|c|}{ Overall Adoption Index } & 75.31 & & 66.75 & & 8.56 & 12.82 & $2.94 *$ \\
\hline
\end{tabular}

** Significant at 1 per cent level of significance

* Significant at 5 per cent level of significance

of scheme helped by linking the beneficiaries to get subsidies from allied state government department to installation of biogas plant.

\section{Overall adoption of recommended dairy farming practices}

Most of beneficiaries (43.33\%) and majority of non-beneficiaries $(62.50 \%)$ had fallen in medium and low adoption category in all aspects (breeding, feeding, health, management and waste management) regarding improved dairy farming practices (Table $1)$, respectively.

The findings also indicated that, 35.00 and 21.67 per cent of the beneficiaries of scheme were having low and high level of adoption in all aspects of recommended dairy farming practices, respectively. On the other hand, among non-beneficiaries, 19.17 per cent had medium level of adoption and only 18.33 per cent non-beneficiaries had high level of adoption in all aspects of recommended dairy farming practices. This indicated that adoption level of beneficiaries were higher as compared to nonbeneficiaries.

\section{Comparison of respondent's extent of Adoption of recommended dairy farming practices based on Adoption Index (AI)}

A perusal of Table 2 shown that in case of beneficiaries, the breeding practices were ranked first with adoption index (AI) 81.83 , which was followed by health practices and feeding practices which were ranked II and III with adoption index 78.96 and 76.98 , respectively. While general management practices were ranked IV with adoption index 73.70 and waste management practices had ranked last with adoption index 56.94. The overall AI of recommended dairy farming practices was 75.31 of beneficiaries. On the other hand, among the non-beneficiaries, maximum adoption in the breeding practices which ranked first with adoption index (AI) 73.08 of recommended dairy farming practices. The feeding practices and health practices were ranked II and III, with adoption index 70.83 and 67.19 , respectively. While the general management practices and waste management practices had 65.99 and 48.89 adoption index which ranked IV and $\mathrm{V}$, respectively in extent of adoption of recommended dairy farming practices.

It also observed that, in both beneficiaries and non-beneficiaries, the adoption index was higher in breeding practices as most of the respondents had adopted the recommended breeding practices like keeping crossbred dairy animal; practicing AI in the animals at proper time of heat; practicing pregnancy diagnosis between 45-120 days after service; breed improvisation through selective breeding at farm level and practicing cow served within 60-90 days after calving. Whereas, adoption index was lowest in waste management practices due to the reason that recommended waste management practiced like dung pit availability for waste management (Ponnusamy et al, 2019); biogas production and vermi-compost making practices were not adopted by the most of dairy farmers. It could be observed from Table 1 that the overall adoption index of recommended dairy farming practices of beneficiaries (75.31) was found to be more compared to nonbeneficiary (66.75). This results is in conformity with finding of Raut (2009) reported the overall adoption index scientific dairy farming practices by farmers was found 65.88 which was line with adoption index of non-beneficiaries of Kamdhenu Dattak Gram Yojana scheme. According to Mande and Thombre (2009) feeding practices for cow possessed more adoption index (57.36) followed by feeding practices for newly born calf (54.83), breeding practices (52.83) and health care practices (40.20). The overall adoption index was 52.17 in Latur district.

The score of adoption index of recommended dairy farming practices of beneficiary dairy farmers over non-beneficiary dairy farmers was found highly significant at 5 per cent level of probability. The beneficiaries had higher extent of adoption which might be due to higher knowledge of improved dairy farming practices, the information and the service provided by the scheme officials on time to farmers lead to creation of desire, interest and conviction to adopt recommended dairy farming scheme due to implementation of Kamdhenu Dattak Gram Yojana. 


\section{Conclusions}

The study concluded that the most of beneficiaries (43.33\%) in medium level of overall adoption and majority of non-beneficiaries $(62.50 \%)$ had fallen in low level of overall adoption category in overall aspects (breeding, feeding, health, management and waste management) regarding recommended dairy farming practices. The overall adoption index of recommended dairy farming practices of beneficiaries (75.31) was found to be more compared to non-beneficiary (66.75) of the scheme. The Kamdhenu Dattak Gram Yojana had created positive impact on the adoption level of the beneficiaries of scheme. Based on the findings and observations, it can be recommend that there is need to increase exposure visits, demonstrations of different technologies, organizing campaigns, create more awareness through various extension literature as well as by providing on campus training programmes on improved dairy farming practices to dairy farmers which motivate them to higher adoption in non-adopted villages of scheme. Secondly, exposure and use of ICT tools such as mobile internet and various social media platforms for easy asses to good quality dairy farming practices and information of different scheme of government to both in adopted and nonadopted villages of Kamdhenu Dattak Gram Yojana. In order to increase dairy farming production and productivity, it is essential to provide input services (breeding, feeding, management and health care) at the farmers' door and create awareness among the dairy farmers about the new technologies through a strong Animal Husbandry Extension Network system.

\section{References}

Divekar BS, Trivedi MM, Dhami AJ (2016) Adoption of improved animal husbandry practices by dairy farmers of Kheda district in Gujarat. Int J Sci Environ Technol 5: 4268 - 4276

GOM (2019). Economic survey of Maharashtra. directorate of economics and statistics, Mumbai, Maharashtra.

Mande JV, Thombre BM (2009) Adoption of cattle rearing practices by dairy cattle owners in Latur district. J Dairying Foods H S 28: 176180

Parihar K, Verma J and Kumar A (2019) Extent of Adoption of Scientific Dairy Farming Practices in Khargone District of Madhya Pradesh. Int Arc Appl Sci Technol 11: 40-44.

Ponnusamy K., Chakravarty R, Singh Sohanvir. (2019. Extension interventions in coping of farmers against effect of climate change in dairy farming. Indian J Dairy Sci 72: 430-436

Ponnusamy, K., and Devi, M.K. (2017). Impact of Integrated Farming System Approach on Doubling Farmers' Income. Agric Econ Res Rev 30: 233-240

Raut A (2009) Retrospect and prospects of commercial dairy farming in Maharashtra. Thesis PhD (Ag.), (Unpub.), NDRI, Karnal, India.

Singh S, Ram Kumar and Meena BS (2018) Adoption level of scientific dairy farming Practices by dairy farmers of Haryana. Indian Res J Ext Edu 10: 45-48 